\title{
REDES DE TRABALHO E CONFIANÇA EM UMA FEIRA DE ROUPAS
}

\author{
NETWORKS OF WORK AND RELIABILITY AT A CLOTHING TRADE FAIR \\ REDES DE TRABAJO Y CONFIANZA EN UNA FERIA DE ROPA
}

\author{
Renata Guimaräes de Carvalho* \\ Regina Heloisa Maciel ${ }^{*}$ \\ Tereza Glaucia Rocha Matos ${ }^{* *}$
}

\begin{abstract}
RESUMO
Este estudo tem como objetivo identificar redes sociais, especificamente redes de trabalho e de confiança, entre comerciantes de uma feira de roupas. Trata-se de uma pesquisa qualitativa, com uso de observação, de entrevistas e de análise de conteúdo para tratamento dos dados. Utiliza-se também de técnicas de mapeamento de características relacionais e estruturais de redes sociais. Como resultados, constatou-se a existência de redes de trabalho e de confiança no dia a dia das interaçôes entre feirantes, mobilizadas por meio de capital social, e sendo um arranjo importante na ordenação cotidiana de seu trabalho. As redes sociais envolvem laços familiares e de amizade, além de vínculos de trabalho remunerado. Identificou-se a formação de relações de ajuda e de reciprocidade entre feirantes de bancas diferentes, apresentando um contraponto às vivências de individualismo e de fragmentação social presentes na cultura do capitalismo flexível.
\end{abstract}

Palavras-chave: Redes sociais. Trabalho. Confiança. Informalidade.

\begin{abstract}
This study aims to identify social networks, specifically nets of work and trustability, among stallholders in a clothing fair. It is a qualitative research, using observation, interviews and content analysis to interpret the collected data. It also uses techniques to map relational and structural characteristics of social networks. The results showed the existence of work and trustability nets in the daily interactions among the fair stallholders, set into action through social capital, exercising an important arrangement in the everyday ordering of their work. Social networks involve family and friendship ties in addition to paid-work relationships. The study pointed out the development of helpful relations and reciprocity among fair stallholders from different
\end{abstract}

Texto recebido em 28 de março de 2016 e aprovado para publicação em 21 de fevereiro de 2017.

* Professora no curso de Psicologia da Universidade Federal do Ceará (UFC), Campus Sobral. E-mail: renatagui.carvalho@ufc.br.

** Professora no Programa de Pós-Graduação em Psicologia (PPGP) da Universidade de Fortaleza (Unifor). E-mail: reginaheloisamaciel@gmail.com.

*** Professora no PPGP da Unifor. E-mail: terezamatos@unifor.br. 
stands, featuring a counterpoint to the experiences of individualism and social fragmentation existing in the culture of flexible capitalism.

Keywords: Social networks. Work. Trustability. Informality.

\title{
RESUMEN
}

Este estudio tiene como objetivo identificar las redes sociales, específicamente las redes de trabajo y de confianza, entre comerciantes de una feria de ropas. Es una investigación cualitativa, que usa la observación, entrevistas y el análisis de contenido para el tratamiento de los datos. También utiliza técnicas de mapeo de características relacionales y estructurales de las redes sociales. Como resultado, se encontró la existencia de las redes de trabajo y de confianza en las interacciones diarias entre feriantes movilizadas a través del capital social, siendo un importante arreglo en la ordenación diaria de su trabajo. Las redes sociales implican los lazos familiares y de amistad además de relaciones de trabajo remunerado. Se identificó la formación de relaciones de ayuda y de reciprocidad entre feriantes de distintas bancas, presentando un contrapunto a las experiencias de individualismo y de fragmentación social existentes en la cultura del capitalismo flexible.

Palabras clave: Redes sociales. Trabajo. Confianza. Informalidad.

\section{INTRODUÇÃO}

\begin{abstract}
$\Lambda$ proposta deste artigo é delinear as redes sociais existentes entre feirantes que trabalham em uma feira de roupas da cidade de Fortaleza-CE. Em 1 geral, eles atuam na informalidade, e as redes possibilitam a construção de relações laborais que permitem dar sentido a uma realidade de trabalho diferenciada.
\end{abstract}

A informalidade laboral é, até certo ponto, decorrente das transformações do trabalho na atualidade, que envolvem os processos de precarização e reestruturação produtiva (Antunes, 2006), flexibilização (Sennet, 2005) e desmonte da sociedade salarial, que se baseava na associação direta entre emprego e cidadania (Castel, 2005). Nesse contexto, os contratos atípicos de trabalho tornaram-se comuns, mesmo em países centrais do capitalismo, sendo caracterizados pela ausência do contrato assalariado típico, com tempo indeterminado de duração e proteções sociais, e pela precariedade das condições de trabalho (Galeazzi, 2006). As transformações laborais ligadas à flexibilização capitalista acarretaram mudanças no modelo tradicional de emprego e nos direitos sociais daí decorrentes, que aumentaram a instabilidade e intensificaram a sensação de insegurança social, de individualismo, de fragilidade de laços sociais, gerando uma cultura imediatista focada no presente (Castel, 2005; Sennet, 2005). 
A informalidade está inserida nesse panorama, embora se deva tomar o cuidado de não compreender o fenômeno como uma consequência linear e direta do processo de precarização. $\mathrm{O}$ conceito de informalidade associa-se inicialmente à definição de "setor informal", termo surgido na década de 1970 para explicar práticas capitalistas atípicas em países subdesenvolvidos (Alves \& Tavares, 2006; Lomnitz, 2009; Krein \& Proni, 2010). Considerava-se que o setor informal era composto por unidades econômicas com baixa produtividade e aplicação de capital, contemplando pequenos empreendimentos familiares, gerados por meio de recursos próprios do trabalhador.

A noção de economia informal buscou superar a dualidade entre setor informal e formal, destacando as condiçôes precárias da informalidade e a ausência de direitos sociais. As atividades informais estão inseridas, fortemente, no movimento de reestruturação produtiva e de aumento da precarização do trabalho, especialmente a partir das décadas de 1980 e 1990. Nos moldes atuais, surge a ideia de uma "nova informalidade" que passa a integrar o processo de flexibilização dos contratos de trabalho e das relações de emprego disfarçadas, mediadas por microempresas, falsas cooperativas, trabalho terceirizado e até vínculos de estágio (Krein \& Proni, 2010).

Para Lomnitz (2009), a informalidade é um campo heterogêneo que reflete ações efetivadas à margem das normas do Estado por pessoas que não têm suas necessidades econômicas e sociais satisfeitas e, por isso, buscam meios e estratégias para viver nessa realidade. Assim, o trabalhador informal cria práticas e processos organizativos estabelecidos no cotidiano (Spink, 1996) que definem arranjos e normas compartilhadas que permitem a continuidade de sua atividade e sua sobrevivência material (Conserva, 2004; Garcia et al., 2010; Sato, 2012).

Um dos arranjos que pode ser destacado nesse ambiente é a formação e o funcionamento de redes sociais produtivas. Pesquisas com trabalhadores na informalidade (Conserva, 2004; Santos, Maciel, \& Sato, 2014; Sato, 2012) apontaram para a existência de redes sociais entrelaçadas às suas práticas de trabalho, principalmente por meio de laços familiares, de amizade e de confiança. As redes articulam e fazem funcionar normas de convivência, apoio mútuo e modos de organização laboral. Elas ampliam a capacidade de estabelecer conexóes e intercâmbios de elementos materiais e simbólicos. Essas conexôes, por sua vez, favorecem o estabelecimento de modos de trabalho e de reconhecimento, fundamentais para a formação de laços entre os trabalhadores e a continuidade das atividades laborais.

Buscando compreender melhor o fenômeno da mobilização de redes sociais no trabalho informal, nesta pesquisa, foi usada a abordagem da Análise de Redes 
Sociais (ARS), que envolve teorias, modelos e aplicaçôes e cujo foco de interesse está nas relações, sobretudo na estrutura das conexões criadas (Hanneman, 2001; Lemieux \& Ouimet, 2012; Wasserman \& Faust, 1994). No Brasil, o uso da ARS contempla temas diversificados, como estudos sobre pobreza urbana, inserção no mercado de trabalho e políticas públicas (Marques, 2012); formação de redes socioprodutivas (Santos et al., 2014); funcionamento de redes sociais em organizações formais (Macambira, Bastos, \& Rossoni, 2015); saúde (Mesquita, Morano, Landim, Collares, \& Pinto, 2012); e colaboração em redes de pesquisadores de pós-graduação (Neiva, Fussi, \& Corradi, 2016).

As redes sociais são formadas por nós, denominados de atores, que podem ser pessoas, grupos e instituições, que estabelecem laços entre si e efetivam um sistema de troca de conteúdos materiais e imateriais, como recursos financeiros ou informaçãa. As ações dos atores são interdependentes e não unidades autônomas. Assim, para entender seu comportamento, é mais importante a análise de como são construídas as relações do que a compreensão de suas características isoladas. Como exemplos de redes sociais estão as relações de amizade e de confiança entre indivíduos, intercâmbios de negócios em organizações, ou vínculos entre famílias em comunidades (Scott, 2000; Wasserman \& Faust, 1994).

Os laços relacionais se constituem por meio de normas sociais e de processos de trocas, base para o funcionamento das redes sociais. Os laços considerados mais fortes são aqueles que envolvem afetividade, algum tempo de convivência e frequência da interação, contemplando, geralmente, relações de parentesco, conjugabilidade e amizade. Os laços fracos referem-se aos "conhecidos", em que os contatos são eventuais e há menos proximidade nas interaçôes (Granovetter, 1973).

A análise de redes sociais se encontra associada à teoria do capital social. A noção de capital social parte da ideia de que pessoas podem dispor de recursos, não apenas de natureza econômica, que se originam da capacidade de estabelecer relações em determinados grupos, comunidades ou estratos sociais mais amplos. Confiança, solidariedade e reciprocidade são elementos imprescindíveis na mobilização de capital social e das redes sociais que fazem circular benefícios como informação, proteção, recursos materiais e financeiros, entre muitas outras formas de trocas. Os laços de sociabilidade geram um modo de organização que não só favorece a realização dos objetivos individuais, mas também o fortalecimento do grupo como um todo (Portes, 2000). Assim, o capital social é um valor que se ampara e se constrói a partir de uma coletividade, baseado em solidariedade, confiança e normas de reciprocidade presentes em redes sociais (Fazito \& Soares, 2013). 
Diante desse contexto, é intuito deste estudo ampliar a compreensão sobre o funcionamento de redes sociais em ambientes laborais que estariam, a princípio, excluídos do modelo tradicional de emprego formal. Dessa forma, buscou-se delinear redes sociais entre trabalhadores informais, especificamente redes de trabalho e de confiança, no ambiente de uma feira de roupas. Optou-se pela realização de uma pesquisa empírica na feira de roupas, por ser um ambiente característico da informalidade e que cresce a cada ano.

\section{MÉTODO}

Trata-se de uma pesquisa de caráter qualitativo, contemplando os seguintes aspectos: a realização da coleta de dados em ambiente natural, próprio do cotidiano dos participantes, com o intuito de apreender sua realidade singular e social; e a utilização de uma ou mais estratégias de investigação (Creswell, 2007). $\mathrm{Na}$ análise das redes, foram empregados dados quantitativos, mas sempre como suporte para a análise qualitativa dos fenômenos investigados (Silverman, 2009).

\subsection{Participantes}

Foi escolhido para a investigação empírica um galpão coberto que se constitui em um dos espaços da feira de roupas, localizada no centro da cidade de Fortaleza-CE. O galpão investigado comporta aproximadamente 500 bancas que se organizam em grandes corredores para a exposição de mercadorias. As confecções são o principal produto à venda no galpão, mas também são vendidos calçados, bolsas e acessórios.

Para participação na pesquisa, buscaram-se feirantes que estavam vendendo produtos no galpão no momento da coleta de dados. Foram excluídos outros trabalhadores da feira, como carregadores, seguranças e vendedores ambulantes de produtos diversos, e também os feirantes que exerciam seu trabalho por um vínculo empregatício formal, com carteira assinada. Os participantes foram escolhidos por conveniência, considerando a sua disponibilidade em participar da pesquisa. Buscou-se também entrevistar feirantes indicados por quem já tinha sido entrevistado, desde que trabalhassem em bancas dentro do galpão em estudo, com o intuito de ampliar as redes detectadas.

Dessa forma, foram entrevistadas 11 feirantes que atuavam em 7 bancas do galpão. O número de participantes, dada a complexidade do estudo de redes, mostrou-se compatível com o delineamento da pesquisa, uma vez que o objetivo não comporta generalizaçôes, mas sim o tracejamento das redes de relaçóes e seu 
funcionamento. Todos os participantes eram mulheres, o que não foi intencional, mas reflete uma expressiva participação feminina na feira.

A idade das participantes variou entre 21 e 56 anos, sendo a média de 31 anos. A maioria (6) se declarou casada ou com companheiro estável e 5 se declararam solteiras. Em relação à escolaridade, a maioria (6) tinha o ensino médio completo, 4 o ensino fundamental e 1 ensino superior.

A média de tempo de trabalho como feirante era de 7,5 anos e, como feirante no galpão, de 3,5 anos. Sobre a faixa de remuneração pessoal conseguida por meio do trabalho na feira, 5 feirantes declararam receber entre $\mathrm{R} \$ 600,00$ e $\mathrm{R} \$$ 1.350,00; as 6 feirantes restantes se distribuíram nas demais faixas de renda (2 abaixo de $\mathrm{R} \$ 600,00 ; 1$ entre $\mathrm{R} \$ 1.350,00$ e $\mathrm{R} \$ 2.250,00 ; 2$ entre $\mathrm{R} \$ 2.250,00$ e R\$ 4.000,00; e 1 entre $\mathrm{R} \$ 4.000,00$ e $\mathrm{R} \$ 7.800,00)$. A maioria (9) não pagava por nenhum tipo de proteção trabalhista; 2 se declararam vinculadas ao programa empreendedor individual.

A maioria das feirantes (7) era dona do ponto de sua banca, de modo individual ou em parceria. As demais (4) trabalhavam apenas como vendedoras e ganhavam por dia de trabalho. Entre as donas de banca, 5 eram fabricantes das mercadorias vendidas e 2 vendiam produtos adquiridos de fornecedores.

\subsection{Instrumentos e procedimentos}

Como técnicas para a coleta de dados, foram empregadas a observação e as entrevistas (Silverman, 2009). Os sujeitos, o cenário e o comportamento social que se desenrolam no espaço da feira e, sobretudo, as condições de trabalho foram o foco da observação. Para registro dos dados foram utilizadas notas de campo, geralmente usadas em pesquisas etnográficas, mas que podem ser um recurso valioso nos estudos qualitativos em geral (Gibbs, 2009). As notas de campo serviram também para registro das experiências e vivências ocorridas durante o processo de coleta de dados, como a postura do entrevistado e informaçóes adicionais fornecidas depois de terminada a gravação da entrevista.

As entrevistas continham três partes. $\mathrm{Na}$ primeira, foi solicitado às entrevistadas que respondessem a um breve questionário sociodemográfico laboral, apenas para caracterização das participantes (resultados descritos acima); na segunda parte, buscou-se o acesso às experiências das participantes por meio das categorias "modos de ordenação do trabalho", "laços, trocas e normas" e "sentidos do trabalho". A terceira parte focou no mapeamento das redes, por meio de um "gerador de nomes". A técnica consiste em solicitar ao respondente, denominado de ego, que indique nomes de pessoas com quem mantem laços 
de trabalho e de confiança na feira, os alters, e descreva as ligações existentes entre si (ego) e os alters citados. Optou-se, assim, pela investigação e desenho de "redes egocentradas", estruturadas com base nas indicaçôes de um ator central, explorando as conexões entre o ego e os alters (Hanneman, 2001).

Para análise das entrevistas, foi usada a análise de conteúdo, especificamente, a análise categorial temática (Bardin, 1977). Como apoio, foi usado o software Atlas TI 6.0 (Gibbs, 2009). Foram consideradas na análise tanto as categorias previamente definidas, com base nos objetivos da pesquisa, quanto categorias emergentes dos dados.

Para traçar e definir indicadores das redes sociais, foram utilizados os softwares Ucinet 6.0 e NetDraw 2.28 (Borgatti, Everett, \& Freeman, 2002). Foram usados indicadores como tamanho da rede (expresso pela quantidade de nós e de laços) e centralidade, especificamente o "grau de entrada", que expressa a soma das indicações recebidas por determinado ator. $\mathrm{O}$ grau de entrada foi considerado o principal indicador de centralidade, pois revela o ator considerado mais importante na rede. Além disso, buscou-se identificar tipos de laços e sua intensidade, elementos intermediados e laços recíprocos. Em relação à intensidade dos laços, observaram-se os critérios definidos por Granovetter (1973) como tempo de vínculo, intensidade emocional, intimidade e serviços recíprocos prestados.

Todas as entrevistas foram gravadas em áudio e transcritas para melhor registro e aproveitamento dos dados, sendo resguardados o sigilo e a identidade dos sujeitos participantes. A transcrição do áudio das entrevistas foi literal, com elementos da fala coloquial (Gibbs, 2009).

Consideraram-se na pesquisa os aspectos éticos presentes na Resolução no 466/12 do Ministério da Saúde, envolvendo pesquisa com seres humanos. Todas as entrevistadas que concordaram em participar da pesquisa assinaram o termo de consentimento livre e esclarecido que descreve as características da pesquisa e suas principais orientações.

\section{RESULTADOS E DISCUSSÃO}

\subsection{Mapeando redes de trabalho e de confiança na feira de roupas}

Seguindo o que foi disposto no método, as redes de trabalho e de confiança mapeadas foram baseadas em duas redes ampliadas. Ressalta-se que, nos diagramas das redes, os nós, em formato de triângulo, representam os egos entrevistados; os quadrados, os alters citados; e as linhas mais espessas indicam os laços familiares. 
As redes de trabalho e de confiança da rede ampliada 1 foram construídas por meio das entrevistas com as feirantes BAT (Ego 1), VNE (Ego 2), SDP (Ego 3), REG (Ego 4) e CCA (Ego 5), que fazem parte da mesma banca, denominada de banca A. Fizeram também parte das redes os nós MD (mãe de BAT e sogra de SDP) e P, uma funcionária que não foi entrevistada.

A banca A existe há seis anos, sendo uma das primeiras sediadas no galpão. Trata-se de uma banca com bastante espaço, em uma localização privilegiada. Seus principais produtos são blusas de malha de diversos modelos e cores. A banca tem uma forte atuação familiar, tendo já sido composta por pais, filhos e cunhados.

$\mathrm{Na}$ época da coleta de dados, tinha três donas, BAT, SDP e MD, que atuavam em sociedade. BAT e sua cunhada SDP se revezavam na banca nos dias de feira juntamente com mais quatro funcionárias que atuavam como vendedoras; a terceira sócia, $\mathrm{MD}$, não ia mais à feira. As funcionárias não tinham carteira assinada e ganhavam por dia de trabalho na feira (diária), podendo também atuar como auxiliares de costura.

A rede de trabalho tem um total de 7 nós, contando com as 5 entrevistadas (egos) e os 2 alters citados (figura 1).

Figura 1 - Diagrama da rede de trabalho da rede ampliada 1

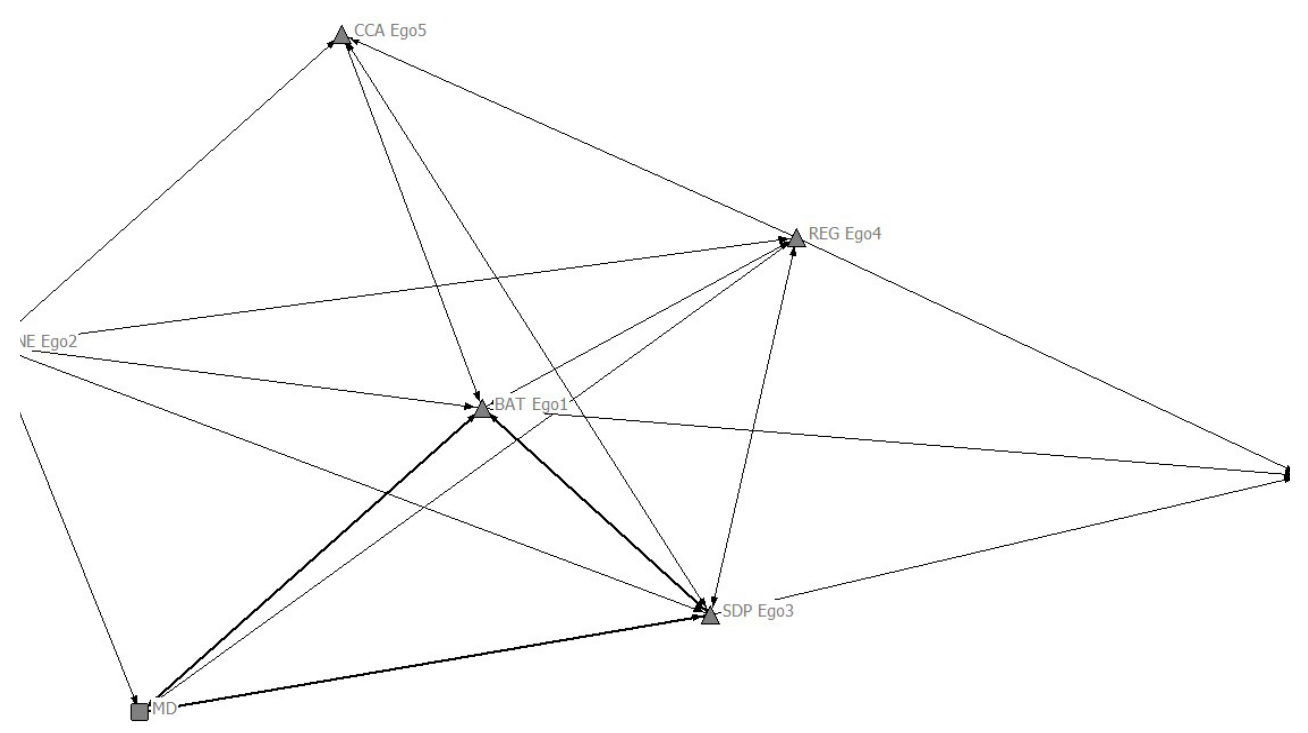

Fonte: elaborado pelas autoras.

São 27 laços entre os atores, que envolvem além do trabalho, vínculos familiares e de amizade que unem as trabalhadoras da banca. Assim, os elementos intermediados na rede apontam para aspectos imateriais, como amizade, e 
materiais, como remuneração. A sócia $\mathrm{MD}$ tem uma presença forte na rede de trabalho, tendo sido indicada como uma das pessoas que mais ajudam no trabalho, mesmo não sendo mais atuante na feira. Além de ser uma das donas da banca A e fazer parte da família, ela se mostra uma figura de referência para as trabalhadoras da banca.

Considerando apenas os egos, os atores mais centrais são BAT e SDP, donas da banca, e VNE, uma funcionária, com $100 \%$ das indicações possíveis. CCA e REG são os atores menos centrais, com $75 \%$ das indicações possíveis. A rede de trabalho forma 8 laços recíprocos envolvendo todas as feirantes entrevistadas atuantes na banca. Esses são indícios que apontam para uma expressiva coesão na rede e nas trocas de trabalho entre as feirantes.

A rede de confiança tem um total de 7 nós, contando com as 5 entrevistadas (egos) e os 2 alters citados. Esses nós geram 24 laços relacionais, como representado no diagrama da rede (figura 2).

Figura 2 - Diagrama da rede de confiança da rede ampliada 1

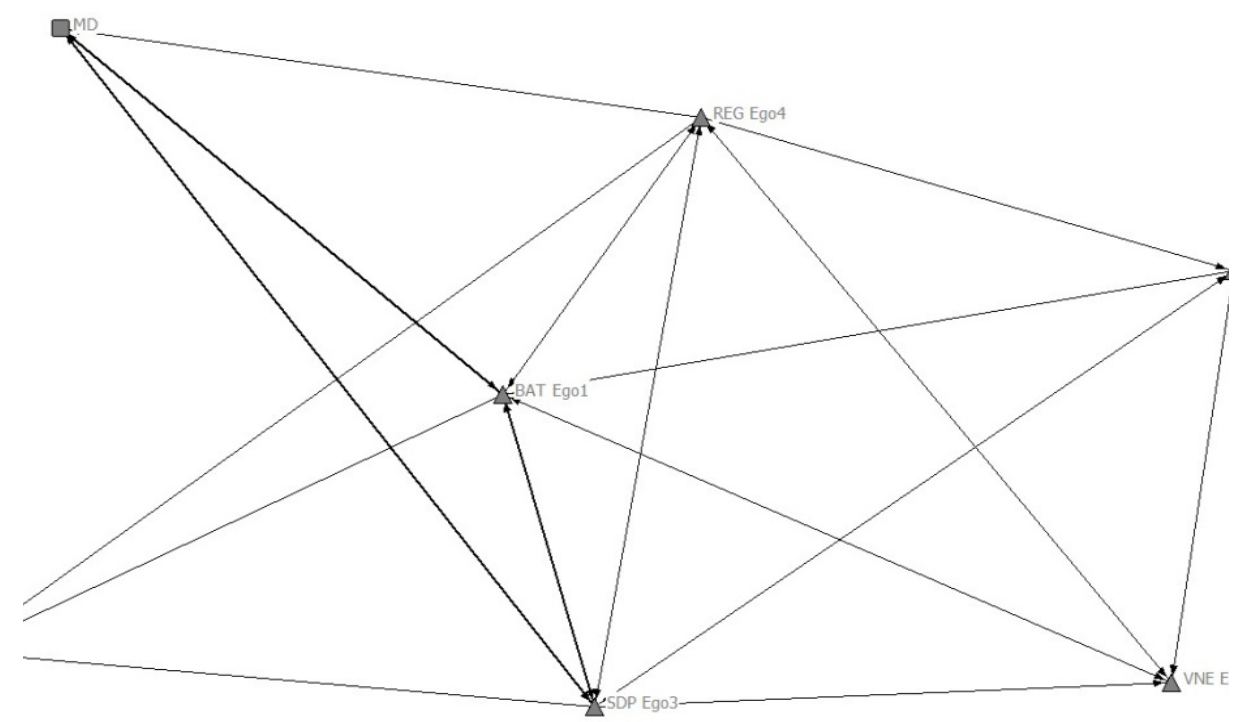

Fonte: elaborado pelas autoras.

Os egos que receberam mais indicaçôes de confiança, e por isso foram considerados mais centrais na rede, foram BAT e VNE, com 100\% das indicações possíveis, seguidas de SDP e REG, com 75\%. Entre os egos, CCA é a menos central, com $50 \%$ das indicaçôes; ressalta-se que CCA é a funcionária com menos tempo de trabalho na banca. A rede de confiança forma 6 laços recíprocos que contemplam novamente as feirantes entrevistadas atuantes na banca.

Observa-se que, nas redes de trabalho e de confiança da rede ampliada 1, os laços unem apenas os membros da banca $\mathrm{A}$, sejam as donas ou as funcionárias. 
Essas características podem estar associadas à forte influência dos laços familiares na condução e no gerenciamento da banca, e também ao porte da banca, com vendedoras fixas. Nota-se também diferenças em relação aos dois diagramas: a rede de trabalho é mais centralizada que a rede de confiança, mostrando que a dimensão confiança acaba sendo pautada por escolhas e não por imposições.

As redes de trabalho e de confiança da rede ampliada 2 foram delineadas com base nas entrevistas com RGS (Ego 6), LMO (Ego 7), FJR (Ego 8), GOE (Ego 9), KTS (Ego 10) e FPL (Ego 11), que fazem parte de seis bancas diferentes, localizadas em corredores contíguos, em uma mesma região do galpão. As redes são compostas por feirantes que podiam ser donas de banca ou funcionárias diaristas, mas que atuavam sozinhas nas vendas nos períodos de realização da feira. O produto mais comum das bancas é a confecção feminina. Predomina a fabricação própria de mercadorias, realizada com a ajuda de familiares, e também de profissionais autônomos que prestam serviço e ganham por produção, como cortadores, costureiras e carregadores.

A rede de trabalho da rede ampliada 2 é composta por 12 nós (6 egos e 6 alters), que formam 20 laços. Nessas relações predominam laços de amizade entre feirantes de 11 bancas diferentes, com apenas 1 laço associado diretamente a vínculo laboral (que une FPL à sua funcionária MR). Nesse contexto, destacase a feirante MP, que foi citada por três entrevistadas como fonte de apoio e amizade no trabalho na feira. Essas relações estão representadas na figura 3.

Figura 3 - Diagrama da rede de trabalho da rede ampliada 2

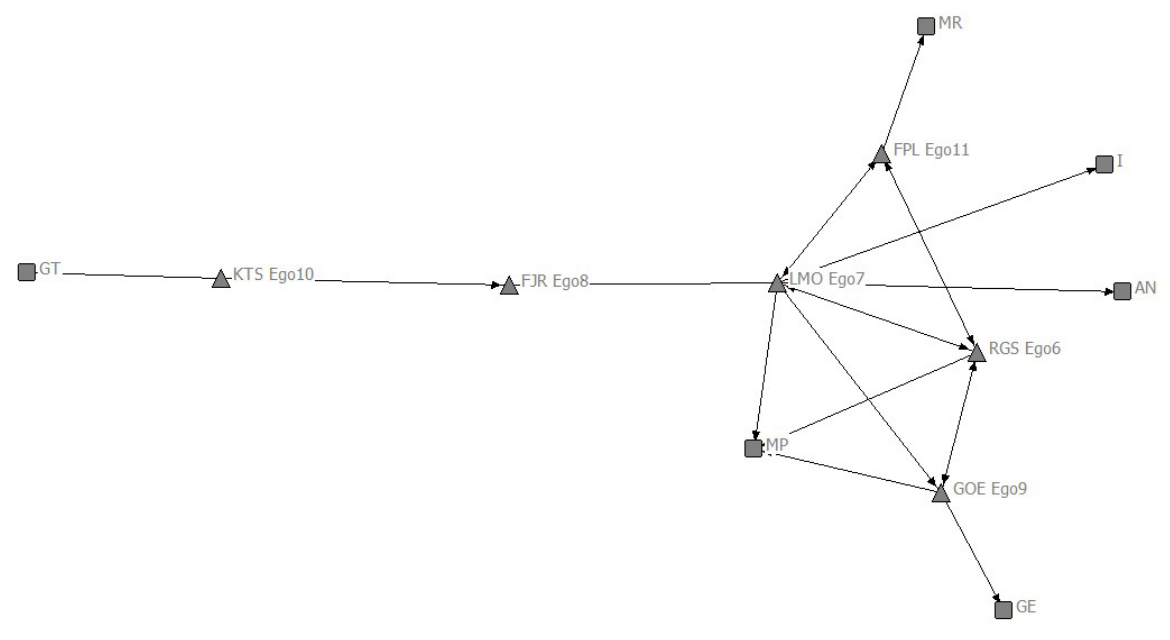

Fonte: elaborado pelas autoras. 
Analisando as relações entre os egos, o ator mais central é RGS, com $60 \%$ das indicações possíveis, e o menos central, KTS, com $20 \%$ das indicações possíveis. LMO, FJR, GOE e FPL detêm 40\% das indicações. A rede de trabalho conta com 5 laços recíprocos, e é interessante notar que todas as feirantes com laços recíprocos são vizinhas de banca.

A rede de confiança é formada por 11 nós e 13 laços (figura 4), com 3 laços recíprocos envolvendo as feirantes RGS, GOE, LMO e FPL.

\section{Figura 4 - Diagrama da rede de confiança da rede ampliada 2}
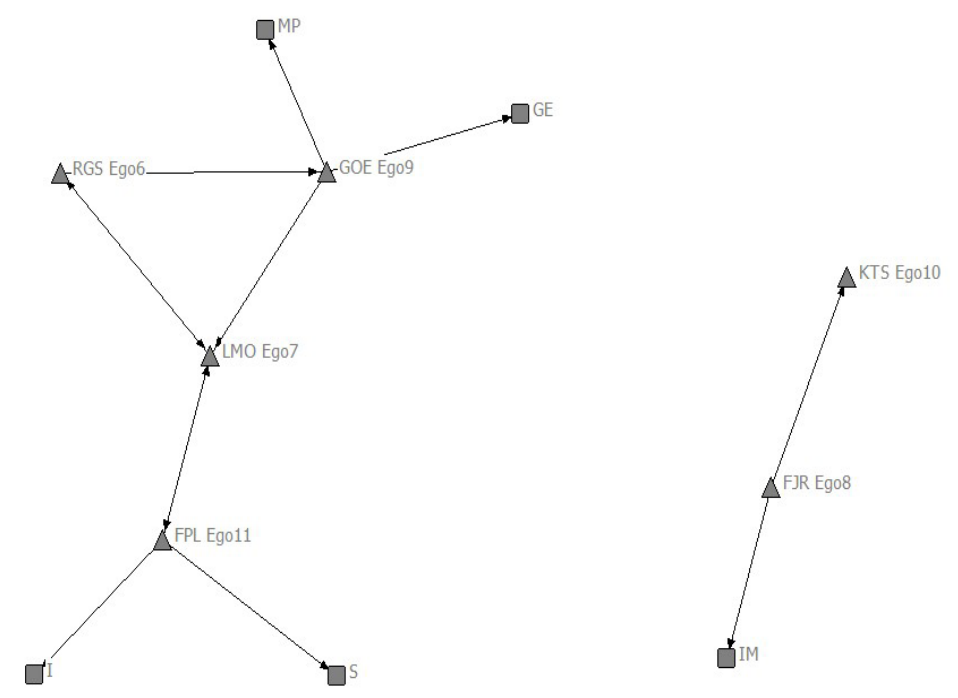

Fonte: elaborado pelas autoras.

Em relação à confiança, a entrevistada mais central é LMO, que recebeu $60 \%$ das indicaçôes possíveis, seguida de RGS, com 40\% das indicações. GOE, KTS e FPL têm $20 \%$ das indicações. FJR é a menos central, não tendo nenhuma indicação.

Interessante notar que, nas redes de trabalho e de confiança da rede ampliada 2, as ligações se expandem por 13 bancas diferentes: 6 bancas de feirantes entrevistados e mais 7 bancas de feirantes citados (GT, GE, I, AN, MP, S e IM). Isso demonstra um padrão de relações de troca específico entre esses feirantes.

Os dois diagramas no caso da rede ampliada 2 também diferem. Novamente aqui, verifica-se que nem sempre as trocas referentes ao trabalho são acompanhadas de confiança mútua. 


\subsection{Redes sociais, trabalho, família, amizade, confiança e reciprocidade entre feirantes}

Para entendimento da relevância das redes sociais no cotidiano das feirantes, buscou-se compreender o que se passa em seu dia a dia de trabalho. Partiu-se da discussão traçada por Spink (1996) sobre as organizações como processos psicossociais que envolvem a ordenação de ações no cotidiano de trabalhadores. De fato, identificou-se um conjunto de arranjos para efetivação da comercialização de mercadorias no espaço da feira de roupas no galpão.

$\mathrm{Na}$ feira, que acontece quatro dias por semana (terça, quarta, sábado e domingo), a prioridade das feirantes é a comercialização da maior quantidade possível de mercadorias. $\mathrm{O}$ trabalho começa com o transporte dos produtos até o galpão, chegando lá por volta de três horas da madrugada. $O$ próximo passo é organizar a exposição das peças, vestir e posicionar os manequins para esperar a chegada dos clientes, geralmente compradores de outros Estados da região Norte e Nordeste. A venda se dá de maneira muito rápida. Não há negociação de preço, pois se argumenta que já é preço de "revenda", e os clientes exigem agilidade do vendedor, já que têm um tempo limitado para realização das compras. Rapidamente a venda é efetivada, as mercadorias são colocadas em sacolas plásticas, e o cliente parte para outras bancas. Como expressa LMO: "Os sacoleiros que vêm de fora querem agilidade do vendedor, eles querem rápido, porque o tempo deles é pouco pra fazer as compras".

A necessidade de chegar de madrugada no galpão e de aproveitar ao máximo o tempo da feira e os fluxos de clientes para a realização do maior número possível de vendas gera uma sobrecarga para as feirantes, principalmente as que ficam sozinhas na banca. "É muito cansativo", resume LMO.

É nesse cotidiano de trabalho que as redes sociais são mobilizadas pelas feirantes. No caso do galpão, duas configurações diferentes foram detectadas. As redes de trabalho e de confiança da rede ampliada 1 se estruturam em torno da banca $\mathrm{A}$, que apresenta características bem diferenciadas. Conta com um forte núcleo familiar que deu origem à banca, envolvendo vários membros da família, trabalhando na gestão, produção e venda de mercadorias, como explica SDP: "Aqui na banca, somos três, eu, a BAT e a minha sogra [...]. As decisões fora daqui, a gente senta e entra num acordo, é como se a gente fosse sócia, entendeu?". Esse dado se alinha a outras pesquisas (Conserva; 2004; Garcia et al., 2010) que apontam o uso do trabalho familiar na organização de unidades produtivas como uma prática bem característica da informalidade, e as negociações, em vez da coerção, como forma de tomar as decisões no trabalho. 
Combinado ao trabalho familiar, existem, na banca vendedoras fixas que se reconhecem como amigas, mas principalmente como funcionárias, como um grupo de trabalho, com divisão de tarefas, multifuncionalidade e autonomia, como expressa a feirante REG: "Aqui é, tipo, dividido: uma pro lado, outra pro outro, e se tiver muito ocupado de contar muita peça, uma conta, outra fica olhando a banca. Nós temos realmente um grupo, porque, se não for assim, não funciona”.

Essas características se combinam a uma quantidade expressiva de laços recíprocos nas indicações de ajuda no trabalho e na confiança, embora a conduta da reciprocidade seja restrita aos membros da banca. Os níveis de centralidade, que podem ser associados a processos de poder, influência e intermediação de recursos (Mizruchi, 2006), estão mais concentrados nas sócias, especialmente em BAT, que é fundadora da banca, e em uma funcionária, VNE, refletindo que o poder hierárquico formal é marcante, mas se mescla a uma liderança informal. Contudo a função de caixa, que exerce o controle sobre o recurso mais importante da banca, o dinheiro, é exclusividade das donas da banca, demarcando uma clara relação assimétrica de poder. Dessa forma, essas redes de trabalho e de confiança apresentam traços característicos, como o laço familiar e de amizade, mas também vínculos de trabalho remunerado que remetem a uma empresa contemporânea, lembrando muito a organização flexível e o trabalho em equipe descritos por Sennet (2005). Essas características da banca A remetem às considerações de Santos et al. (2014) sobre redes socioprodutivas que se organizam inicialmente com uso de apoio familiar e de amigos mais próximos, mas que, ao crescerem, começam a focar mais a produção do que os laços de sociabilidade, encontrandose em uma situação mais próxima de um empreendimento capitalista formal, embora considerando mais vantajoso permanecer na informalidade.

$\mathrm{Na}$ rede ampliada 2, as redes de trabalho e de confiança se espalham por bancas diferentes. São caracterizadas pela amizade, com conversas, brincadeiras, lanches compartilhados, e intermediação de materiais diversos, serviços e ajuda, sobretudo na venda em momentos de maior movimentação de clientes.

A formação dos laços de amizade para trocas mútuas de ajuda envolve afinidades e, principalmente, a localização das bancas. Esse dado remete a dois aspectos analisados por Marques et al. (2013) em pesquisa sobre redes pessoais de moradores de bairros de periferia: a homofilia e o localismo, que se referem, respectivamente, ao movimento de associação entre pessoas com características similares e que estão próximas geograficamente, como vizinhas de bairro. Na feira, as redes de trabalho e de confiança da rede ampliada 2 contemplam efetivamente trabalhadoras que têm afinidade de ofício e de cotidiano de trabalho, com suas realizações e adversidades, e que são vizinhas de banca, ocupando os mesmos 
corredores no galpão. Como expressa RGS: "Quando a gente tá aperreada pra vender, uma vem, ajuda, olha a banca, vai comprar merenda". Ou LMO: "Eu venho só. Num dia que tem um movimento muito grande, elas vêm me ajudar a vender pra aquele cliente, se eu precisar de alguma coisa, elas tendo, elas me cedem". As feirantes vizinhas de banca são as que estão mais próximas e podem ajudar mais prontamente em caso de necessidade.

Essas feirantes seguem a conduta da reciprocidade. Como expressa KTS: "A gente aqui é assim: uma ajuda a outra"; ou FJR: "A gente se ajuda. Quando uma não vende, a outra puxa cliente, puxa pra cá [...] Quando eu quero uma coisa ou ela é assim, uma servindo a outra”. O reconhecimento da igualdade de condições é um dos aspectos fundamentais na reciprocidade em relações solidárias (Lomnitz, 2009). No espaço da feira, trabalhadoras se reconhecem com atividades, recursos e dificuldades similares e se dispóem a uma forma de associação. As dificuldades individuais, quando articuladas em uma coletividade de trabalho, são diluídas por meio de processos de trocas e ajudas mútuas. Apesar das distinções entre as feirantes em relação à sua função como donas de banca ou funcionárias, considera-se que, nas redes de trabalho e de confiança entre feirantes de bancas diferentes, predomina uma forma de reciprocidade na qual todos se veem em situação de igualdade e estão dispostos a ajudar. Como afirmam Luna e Velasco (2005), são redes em que nenhum ator tem autoridade absoluta e todos contam com uma certa autonomia. Por conta dessa característica, os níveis de centralidade são mais baixos e mais diluídos entre os membros das redes.

Todas as entrevistadas das redes de trabalho e de confiança da rede ampliada 2 se conheceram no galpão e construíram os laços de amizade baseados no trabalho. Nessas redes predominam relações que formam laços recíprocos em menor quantidade que na rede ampliada 1 , indicando relaçôes mais fluídas, com laços mais fracos (Granovetter, 1973). Isso pode ser explicado pela necessidade de estabelecimento de relações mais amplas, envolvendo mais feirantes nos processos de ajuda, como pondera GOE: "Eu tive que sair para ir ao banco, aí a RGS fica olhando minha banca, quando a RGS não tá, aí a MP. Só que a MP hoje não veio, quem tá é a GE, que também é de confiança”.

O que possibilita que esses laços mais fracos formem relações de ajuda mútua é a existência de confiança. Efetivamente, na feira, a confiança se encontra presente, em maior ou menor grau, diminuindo a instabilidade e a necessidade de desgaste de tempo e de energia em negociações constantes nas trocas do dia a dia.

Considera-se que a confiança entre feirantes se apresenta em três dimensões, como destacado por Luna e Velasco (2005): a pessoal/normativa, baseada em 
uma maior proximidade e intimidade; a estratégica/calculada, fundamentada em normas de reciprocidade; e a baseada em capacidades/prestígio. Entende-se que, na feira, a confiança está presente em relações pessoais mais próximas, com quem realmente "se pode conversar" e nos vínculos familiares, como no caso das sócias da banca A; nas relações de trabalho/ajuda baseadas na reciprocidade; e na expectativa de capacidade para a efetivação das vendas, envolvendo feirantes de bancas diferentes, ou mesmo as funcionárias que desempenham seu trabalho na banca A. Essas formas de confiança permeiam as relações na feira de forma dinâmica e até sobreposta, seja nos laços familiares e de amizade que se misturam ao trabalho ou nos vínculos de trabalho que também envolvem amizade.

Considerando que o capital social existe em razão de uma coletividade, constituindo-se como um bem imaterial que contempla solidariedade, confiança e reciprocidade (Fazito \& Soares, 2013; Portes, 2000), pode-se indicar que se articula ao funcionamento das redes sociais na feira, seja por meio de laços fortes familiares ou de laços de amizade, mais fracos e fluidos. Quanto mais as redes baseadas em confiança funcionam em suas trocas, mais se potencializa a formação de capital social entrelaçado às redes e ao trabalho informal, o que pode ser identificado no estudo com as redes socioprodutivas (Santos et al., 2014).

Apesar do ambiente da feira ser competitivo, não se ouviu, em qualquer momento, expressões como "aqui é cada um por si e Deus por todos" ou "o vencedor leva tudo" (Sennet, 2005, p. 168), e sim, "aqui todo mundo se ajuda", "aqui é uma família". Entende-se que esses aspectos ajudam a compor sentidos positivos para o trabalho desempenhado, refletindo as elaborações de trabalhadoras maduras, que têm, em média, sete anos de experiência como feirante.

O reconhecimento da necessidade de ajuda mútua, de interdependência, influencia a mobilização de redes sociais e a criação de capital social. Assim, considera-se que a formação e o funcionamento de redes sociais, especialmente as redes de trabalho e de confiança que fazem uso de práticas de ajuda entre feirantes, se não suprimem a precariedade da atividade realizada, podem fornecer um contraponto as vivências de individualismo, de competitividade e de fragmentação social, que estão presentes na cultura da precarização e do capitalismo flexível (Antunes, 2006; Castel, 2005; Sennet, 2005). 


\section{CONSIDERAÇŌESS FINAIS}

A constatação mais importante, com base nos resultados descritos, é a da existência de redes sociais que atuam no ambiente da feira de roupas no galpão investigado e que remetem diretamente ao trabalho dos feirantes. A quantidade de nós e de laços das redes de trabalho e de confiança demonstra a capacidade de construção e aproveitamento das conexôes já existentes para viabilizar o funcionamento das bancas. Assim, os vínculos entre trabalhadores na informalidade podem ir além das relações familiares e de remuneração e envolver trocas como amizade e confiança que se entrelaçam em um modo peculiar de organização do trabalho, corroborando os resultados dos estudos de Conserva (2004), Santos et al. (2014) e Sato (2012).

Considera-se que a característica das bancas envolvidas nas redes ampliadas 1 e 2 é um fator fundamental no entendimento das diferenças em suas redes de trabalho e de confiança. Para dar conta das demandas da feira, a banca A tem uma estrutura em que não é necessário lançar mão da ajuda de feirantes de outras bancas, já que conta com trabalho familiar e de vendedoras remuneradas. Já no caso das outras bancas pesquisadas, é necessário contar com ajuda adicional para atendimento da demanda, e esse apoio vem de outros feirantes. Isso não quer dizer que as feirantes da banca $\mathrm{A}$ estão imunes à sobrecarga de trabalho e à instabilidade de fluxo de clientes, apenas que têm uma possibilidade diferente de atuar.

Assim, constata-se que as redes sociais atuantes na feira, e que formam modos de ordenação do trabalho que organizam o cotidiano laboral de feirantes, apresentam configuraçôes diferenciadas, coerentes com a própria diversidade do trabalho e suas transformações contemporâneas. Nas redes de trabalho e de confiança provenientes da rede ampliada 1 , com laços familiares mesclados com uma assimilação de aspectos de uma organização flexível contemporânea, e, nas provenientes da rede ampliada 2, com a construção de relações de solidariedade entre feirantes concorrentes.

Além disso, os resultados obtidos nesta pesquisa servem de subsídio para estudos comparativos, em outras realidades de trabalho, aumentando a compreensão sobre o funcionamento das redes sociais em ambientes laborais. Trazem, ainda, o uso de um método de mapeamento de relações sociais, a análise de redes sociais, que pode agregar elementos teóricos e metodológicos em futuros estudos em Psicologia social e do trabalho, ampliando o ensejo de novas pesquisas na área.

Diante do contexto de precarização do mundo do trabalho e seus impactos para o trabalhador, a perspectiva de mobilização de redes sociais aponta para um novo olhar sobre o trabalho e, especificamente o trabalho na informalidade. Não 
mais como um lugar apenas de precariedade e exclusão, mas como um espaço onde associações espontâneas e redes de apoio, como novas formas de resistência social e subjetiva podem aflorar e se desenvolver, oferecendo uma possibilidade de contraponto em relação à cultura do individualismo no capitalismo flexível. 


\section{REFERÊNCIAS}

Alves, M. A. \& Tavares, M. A. (2006). A dupla face da informalidade do trabalho: "autonomia" ou precarização. In R. Antunes (Org.), Riqueza e miséria do trabalho no Brasil. (pp. 425-444). São Paulo: Boitempo.

Antunes, R. (2006). O caracol e sua concha: ensaios sobre a nova morfologia do trabalho. São Paulo: Boitempo.

Bardin, L. (1977). Análise de conteúdo. Lisboa: Edições 70.

Borgatti, S. P., Everett, M. G., \& Freeman, L. C. (2002). Ucinet for Windows: software for social network analysis. Harvard: Analytic Technologies.

Castel, R. (2005). A insegurança social: o que é ser protegido? Petrópolis: Vozes.

Conserva, M. S. (2004). O labirinto da atividade ambulante na cidade de João Pessoa. In A. Araújo, M. F. Alberto, M. Y. Neves, \& M. Athayde (Orgs.), Cenários do trabalho: subjetividade, movimento e enigma. (pp. 270-272). Rio de Janeiro: DP\&A.

Creswell, J. W. (2007). Projeto de pesquisa: métodos qualitativo, quantitativo e misto. Porto Alegre: Artmed.

Fazito, D. \& Soares, W. (2013). Capital social, análise de redes e os mecanismos intermediários do sistema migratório Brasil/EUA. In L. C. Dias \& M. Ferrari (Orgs.), Territorialidades humanas e redes sociais. (pp. 219-241). Florianópolis: Insular.

Galeazzi, I. (2006). Precarização do trabalho. In A. D. Cattani \& L. Holzmann (Orgs.), Dicionário de trabalho e tecnologia. (pp. 203-206). Porto Alegre: Ed. da UFRGS.

Garcia, M. R. V., Segre, A., Baccaro, A. F., Silva, L. M., Costa, L., \& Cândido, M. S. (2010). "Mulheres guerreiras": identidade feminina e profissional entre vendedores ambulantes da cidade de São Paulo. Cadernos de Psicologia Social do Trabalho, 13(1), 27-42. Recuperado a partir de http://pepsic.bvsalud.org/ scielo.php?script=sci_arttext\&pid=S1516-37172010000100004\&lng=pt\&tl $\mathrm{ng}=\mathrm{pt}$

Gibbs, G. (2009). Análise de dados qualitativos. Porto Alegre: Artmed.

Granovetter, M. (1973). The strength of weak ties. The American Journal of Sociology, 78(6), 1360-1380. Recuperado a partir de https://sociology.stanford. 
edu/sites/default/files/publications/the_strength_of_weak_ties_and_exch_wgans.pdf

Hanneman, R. A. (2001). Introducción a los métodos de análisis de las redes sociales. Riverside: Departamento de Sociología de La Universidad de California. Recuperado a partir de http://revista-redes.rediris.es/webredes/text.htm

Krein, J. D. \& Proni, M. W. (2010). Economia informal: aspectos conceituais e teóricos. Brasília: Organização Internacional do Trabalho - Escritório no Brasil. Recuperado a partir de http://www.oitbrasil.org.br/node/241

Lemieux, V. \& Ouimet, M. (2012). Análise estrutural das redes sociais. Lisboa: Instituto Piaget.

Lomnitz, L. A. (2009). Redes sociais, cultura e poder. Rio de Janeiro: E-papers.

Luna, M. \& Velasco, J. L. (2005). Confianza y desempeño en las redes sociales. Revista Mexicana de Sociología, 67(1), 127-162. Recuperado a partir de http:// www.ejournal.unam.mx/rms/2005-1/RMS005000104.pdf

Macambira, M. O., Bastos, A. V. B., \& Rossoni, L. (2015). Redes sociais e o vínculo com a organização: como a estrutura das relações explica o comprometimento, o entrincheiramento e o consentimento. Revista Psicologia Organizaçôes e Trabalho, 15(2), 109-122. Recuperado a partir de http://pepsic.bvsalud.org/ scielo.php?script=sci_arttext\&pid=S1984-66572015000200002\&lng=pt\&nr $\mathrm{m}=\mathrm{iso}$

Marques, E., Bichir, R., Pavez, T., Zoppi, M., Moya, M. E., \& Pantoja, I. (2013). Redes pessoais e pobreza em São Paulo. In L. C. Dias \& M. Ferrari (Orgs.), Territorialidades humanas e redes sociais. (pp. 189-218). Florianópolis: Insular.

Marques, E. (Org.). (2012). Redes sociais no Brasil: sociabilidade, organizaçôes e políticas públicas. Belo Horizonte: Fino Traço.

Mesquita, R. B., Morano, M. T. A. P., Landim, F. L. P., Collares, P. M. C., \& Pinto, J. M. S. (2012). Rede de apoio social e saúde de idosos pneumopatas crônicos. Ciência \& Saúde Coletiva, 17(5), 1125-1133. Recuperado a partir de https://dx.doi.org/10.1590/S1413-81232012000500006

Mizruchi, M. S. (2006). Análise de redes sociais: avanços recentes e controvérsias atuais. Revista de Administração de Empresas, 46(3), 7286. Recuperado a partir de http://www.scielo.br/scielo.php?script=sci_ arttext\&pid=S003475902006000300013\&lng=en\&tlng=pt. 
Neiva, E. R., Fussi, C. C., \& Corradi, A. A. (2016). Relaçôes entre produtividade acadêmica e redes sociais entre pesquisadores da ciência psicológica. Estudos de Psicologia, 33(1), 83-94. Recuperado a partir de http://www.scielo.br/scielo. php?pid=S0103166X2016000100083\&script=sci_abstract

Portes, A. (2000). Capital social: origens e aplicações na sociologia contemporânea. Sociologia, Problemas e Práticas, (33), 133-158. Recuperado a partir de http://www.scielo.mec.pt/scielo.php?script=sci_arttext\&pid=S087365292000000200007\&lng=pt\&tlng=pt.

Santos, J. B. F., Maciel, R. H., \& Sato, L. (2014). Trabalhadores informais e a formação de redes socioprodutivas (RSP): considerações teórico-empíricas. Contemporânea, 4(2), 325-350. Recuperado a partir de http://www. contemporanea.ufscar.br/index.php/contemporanea/article/view/251

Sato, L. (2012). Feira livre: organização, trabalho e sociabilidade. São Paulo: Editora da Universidade de São Paulo.

Scott, J. (2000). Social network analysis: a handbook. (2 ${ }^{\text {nd }}$ Ed.). London: Sage.

Sennet, R. (2005). A corrosão do caráter: as consequências pessoais do trabalho no novo capitalismo. Rio de Janeiro: Record.

Silverman, D. (2009). Interpretação de dados qualitativos: métodos para análise de entrevistas, textos e interaçôes. Porto Alegre: Artmed.

Spink, P. K. (1996). Organização como fenômeno psicossocial: notas para uma redefinição da Psicologia do trabalho. Psicologia \& Sociedade, 8(1), 174-192.

Wasserman, S., \& Faust, K. (1994). Social network analysis: methods and applications. Cambridge: Cambridge University Press. 